\title{
Mediating between practitioner and developer communities: the Learning Activity Design in Education experience
}

\author{
Isobel Falconer* \\ Glasgow Caledonian University, UK
}

The slow uptake by teachers in post-compulsory education of new technological tools and technology-enhanced teaching methods may be symptomatic of a general split in the e-learning community between development of tools, services and standards, and research into how teachers can use these most effectively (i.e. between the teaching practitioner and technical developer communities). This paper reflects on the experience of transferring knowledge and understanding between these two communities during the Learning Activity Design in Education project funded by the UK Joint Information Systems Committee. The discussion is situated within the literature on 'mediating representations' and 'mediating artefacts', and shows that the practical operation of mediating representations is far more complex than previously acknowledged. The experience suggests that for effective transfer of concepts between communities, the communities need to overlap to the extent that a single representation is comprehensible to both. This representation may be viewed as a boundary object that is used to negotiate understanding. If the communities do not overlap a chain of intermediate representations and communities may be necessary. Finally, a tentative distinction is drawn between mediating representations and mediating artefacts, based not in the nature of the resources, but in their mode and context of use.

\section{Introduction}

In recent decades a host of technological tools-such as online conferencing, interactive whiteboards, wikis, and so on-have become available, providing new opportunities to enhance learning (Conole, 2004; Conole \& Dyke, 2004; Collis \& Moonen, 2005). In particular, one supposed benefit of learning technologies is their potential for enabling teaching practitioners (teachers, lecturers, tutors, hereafter referred to as 'practitioners') to implement new teaching methods informed by recent theories of learning (see, for example, Conole \& Oliver, 2007). Yet there is

\footnotetext{
*Caledonian Academy, Glasgow Caledonian University, Cowcaddens Road, Glasgow G4 0BA, UK. Email: isobel.falconer@gcal.ac.uk
} 
little sign that education has changed in any fundamental way despite substantial institutional investment in information and communications technology (Collis \& van der Wende, 2002). Although we now know a great deal about how to teach for effective learning, on the whole didactic modes with a focus on transmission of knowledge still predominate in post-compulsory education-the potential of new technologies to enable new styles of learning is not yet being realised (Britain \& Liber, 2004; Littlejohn, 2004). This may be because the benefits of e-learning as perceived by technical and educational developers (those, generally in support departments, whose role is to promote teaching excellence, develop teaching and learning materials, advise faculty on pedagogic issues, etc.) are not sufficiently clear or easy to communicate to practitioners, as suggested by Beetham (2004; UK Joint Information Systems Committee [JISC], 2006), or because they are not well aligned with existing institutional structures, values and rewards as pointed out by Seufert and Euler (2004)

The solution to these problems is complex and likely to involve institutional change strategically focusing on transformation in learning and teaching practice, support for staff and students engaging in these new practices and implementation of new physical and virtual learning environments (Littlejohn \& Peacock, 2003). A number of these strategic changes are proving difficult for institutions. For example, linking empirically based theory to practice, and recognition of valid outcomes aligned to pedagogical theory, is challenging for practitioners within current organisational constraints. For example, teachers may feel prevented from implementing collaborative teaching methods by the need to align with institutionally imposed learning outcomes based on a didactic approach (Falconer et al., 2007). Similarly, implementing necessary changes in working practices and reward structures to provide sufficient levels of practical support for development of e-learning practice are proving particularly problematic. But all these developments require some sort of translation that makes what the practitioner does on the ground, and its implications, understandable and meaningful in practical terms to those-technical, administrative and managerial-providing the support, facilities and infrastructure (Beetham, 2002). Conversely, the implications of new theories of teaching, and the affordances of new technological tools, need to be translated into terms that teachers and lecturers can put into practice. This translation is frequently achieved through some sort of representation of practice or theory; for example, a case study or model. But it is apparent that different types of representation are likely to be understandable to different types of users-a translation of a teaching practice that informs university management will probably be meaningless to a technical developer. Thus the nature of the communities involved and the purpose of the communication are important factors when considering how best to mediate and translate between them.

\section{Mediating representations}

The term 'mediating representations' is widely used in knowledge systems and cognitive science disciplines (for example, Boose, 1990). I define it as encompassing any 
representation that enhances communication among participants and improves their understanding of a concept or practice.

In an empirically based study, Beetham (2001) discussed the role and usability of such representations in supporting change in teaching practice. Her examples of representations ranged from case studies, guidelines and toolkits to computer software and databases (see Table 1 for a fuller list). She implies a distinction between representations of practice and representations of learning, which might equate to a distinction between representations originated by teachers and representations originated by educational theorists or psychologists. But in her analysis she treats these on the same footing, being entirely concerned with the end users; in this case, teaching practitioners, educational developers and learning technology support staff. While Beetham concentrates only on very limited types of end user, she makes the valuable point that even a single user might have a number of uses or types of interaction with a representation. For example, a teacher might use a case study as a source of information about a pedagogic model, as a straightforward description of a lesson that they can use in their own practice, or as the inspiration for a new teaching approach. Alternatively, the user might require different types of representation to support different sorts of interaction. For example, while a case study might be well suited to providing inspiration for a new teaching approach, it might be difficult to derive an operable description of a lesson from it-a lesson plan might be better suited to the

Table 1. Lists of Beetham's and Sharpe et al.'s mediating representations (based on Beetham, 2001; Sharpe et al., 2004) and Conole's mediating artefacts (from Jones \& Conole, 2006)

Beetham's and Sharpe et al.'s mediating representations

Conole's mediating artefacts

Review
Guidelines
Staff development material
Case study
Framework/toolkit-models,
Article/report
Software-learning
Software-activity shell
Software-learning object
Information resource
Project/service
Databases
Bibliographies
Concept maps

Narratives

Case studies

Peer dialogue

Expert guidance

Knowledge building

Networked communication

Lesson plans

Tips and tricks

Demonstrations

Answer gardens

Frequently asked questions

Schema

Toolkits

Models

Patterns

Roughly speaking, Conole characterises resources by their type and the list runs from the concrete and contextualised to the abstract and conceptual, while Sharpe et al. and Beetham characterize them by their format running from text-based to software-based (Littlejohn et al., 2006). This table is not designed to imply a mapping between the two. 
latter purpose. The alignment between the purpose of a representation and its form is, then, crucial to its success. Beetham's interest in representations as supporting change leads to a classification of six types of interaction (inform, adopt, adapt, create, guide and comment) that implies a learning cycle as practitioners embed the new ideas conveyed by the representation into their practice. Similar cycles have been suggested by Beetham (2002), Conole and Oliver (2001), and Mayes and Fowler (Fowler \& Mayes, 1999; Mayes, 2001). Their work thus emphasises that teachers are in the position of learners when changing practice, and representations need to support the stages of a learning cycle.

Beetham (2001) further characterises the representations along a spectrum that runs from text, such as articles, reviews and case studies, which are highly informative, to software tools such as assessment tools, which are highly adoptable but less informative. Such a counterposition between inform and adopt does not seem immediately obvious, although it parallels the payoff between the acquirability and expressiveness of a representation noted by Boose (1990). Boose uses language as an example: a language that is sufficiently sophisticated to convey complex ideas may be difficult to acquire, while a more basic language is easier to learn but lacks the power to express complex concepts or fine distinctions between concepts. Beetham suggests that these counter-positions are driven by time, or rather lack of time. In a follow-up paper, Beetham (2002) adds the nuance that lack of time is a manifestation of lack of suitable institutional and reward structures. She also discusses explicitly the types of representation that might be used by five different communities of users (learner, teacher, resource developer, educational developer, strategic developer), but she has no further empirical evidence to show how these representations do in fact mediate in interpreting practice across community boundaries.

This problem was taken up by Sharpe et al. (2004), who investigated the transfer of knowledge between the education researcher and practitioner communities. However, as in Beetham's previous survey, the main participants were educational developers and practitioners rather than education researchers. The most effective representations cited appeared to be those around which they could interact with colleagues (i.e. originators and end users were part of the same, or overlapping, communities) - a conclusion that is embedded within our definition of a mediating representation as enhancing communication. However, it leaves unanswered the issue of how representations originating in the academic education research community make their way into the educational developer community in the first place.

Not explored by Beetham, or Sharpe et al., but relevant to this last issue, is the idea of 'boundary objects'. Boundary objects are a concept that originated in actornetwork theory (Star, 1989) and were adopted by Wenger (1998) and Tuomi-Grohn and Engestrom (2003). Boundary objects are common to the communities between whom they mediate, but are viewed in different ways by those communities. They act to bring about coordination and negotiate understanding between the communities, and form a learning space in their own right (Edwards, 2005). To act as a boundary object in this way, the practices of both communities must encompass the object, although not necessarily from the same perspective (i.e. the communities must have 
a common boundary and not be too far removed from each other). If we consider Beetham's or Sharpe et al.'s representations as boundary objects, we can see why they are most effective when used for communication between closely overlapping communities.

Conole (2006; Jones \& Conole, 2006) discusses a very similar list of resources to Beetham (see Table 1), but refers to them as 'mediating artefacts' in an approach that is rooted in activity theory; her work has been followed up by Oliver (2006). Rather than considering the resources as integral to the practices of a community, Conole views them as tools for making decisions. Mediating artefacts will help practitioners decide which technological tools and educational theories are appropriate to their situation and aims. Providing support for this choice, it is argued, will help bridge the gap between recent educational theory and implementation in practice. Despite their different perspectives, however, many of the conclusions of Conole's survey of mediating artefacts, parallel Beetham and Sharpe et al.'s. For example, she draws a continuum from open theoretical maps at one end to restrictive but easy-to-use software tools at the other end. And she notes that the use of models of educational theory has been criticised because practitioners may not understand how to apply them effectively - she is essentially making the same point as Sharpe et al. when they find that the intervention of educational developers is usually necessary between academic theorist and practitioner.

Like Beetham and Sharpe et al., Conole is essentially concerned with practitioners as the users of mediating artefacts, although she does mention learners and technical developers occasionally. However, if we view the DialogPlus toolkit, developed by Conole and others, as a representation (Conole \& Fill, 2005), we begin to see how it might work to mediate between the educational developer and practitioner communities. DialogPlus is an online tool that presents practitioners with a range of options to help them develop effective learning activities (see Figure 1). However, the theory of learning that underpins the process is hidden from the user.

In this case, the educational developer has not intervened in person to interpret a model or theory to the practitioner, but has represented their understanding in the toolkit. This highlights the structural difference between viewing such resources as tools and viewing them as representations: the representation view entails communication between at least two participants, not necessarily both from the same community, whereas the tools view hides the role of one of the participants, embedding it within the tool.

We note here a confusion of terminology — in that activity theory, upon which Conole bases her account, divides mediation by artefacts into 'sign mediation' and 'tool mediation' (for example, Engestrom et al., 1999), with Conole's 'artefacts' corresponding to 'tools' while Sharpe et al.'s and Beetham's use of 'representations' corresponds more closely to 'signs' with its emphasis on communication. However, other authors who have drawn on activity theory, such as Leadbetter (2004), have validly used 'mediating artefacts' to signify resources that are a focus for communication. In the terms of the current paper, Leadbetter's use of resources would count as mediating representations. 


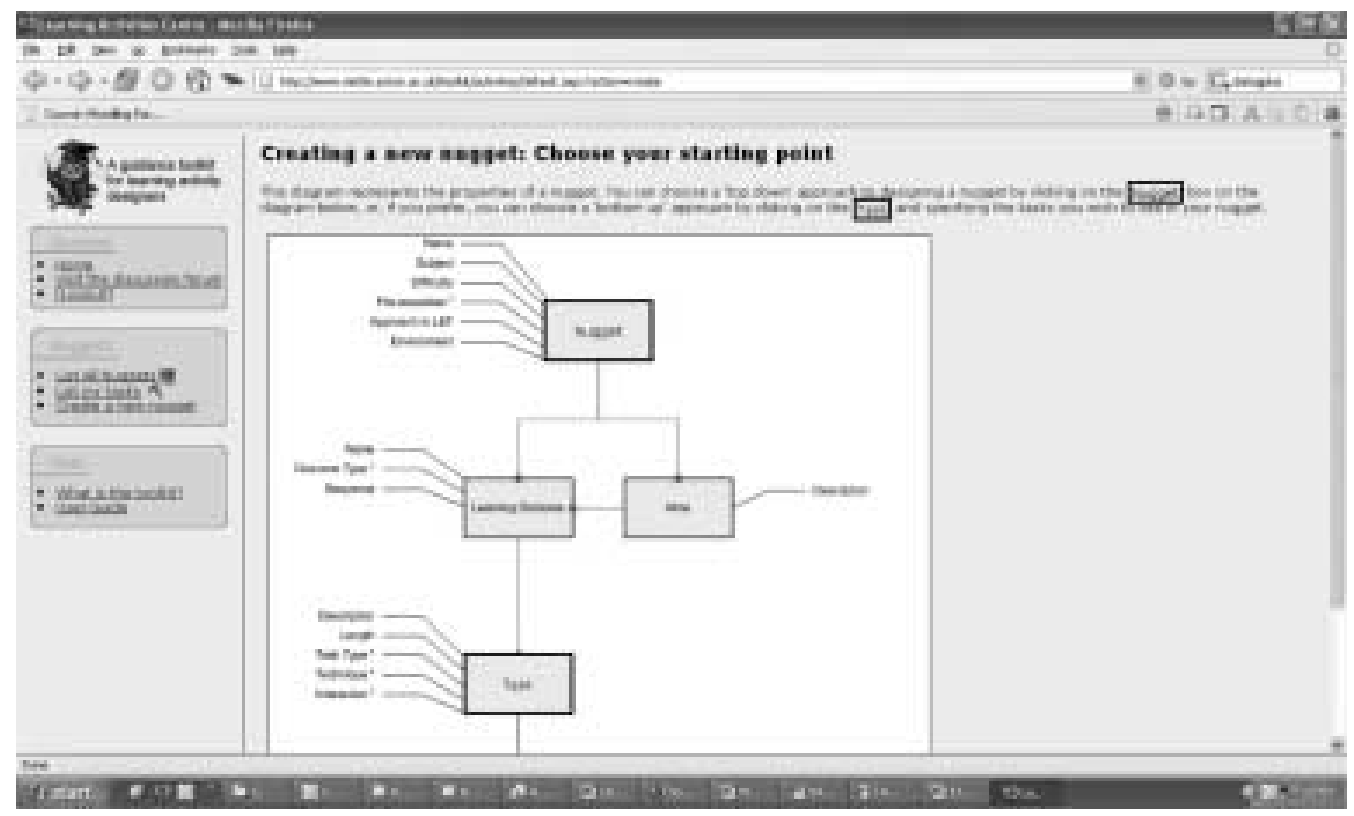

Figure 1. Screenshot of the DialogPlus toolkit intended to help practitioners design technology enhanced learning activities (http://www.nettle.soton.ac.uk/toolkit/activities/default.aspx?action= create)

Other work that uses the language of mediating representations, such as that of Goodyear and Steeples (1998), similarly concentrates on communication between members of a single community, or closely overlapping communities, of practitioners and educational developers. However, Beetham (2004), Sharpe et al. (2004), Seufert and Euler (2004), Oliver (2004), and Scott (2004) have all highlighted the variety of different stakeholders in learning technology, and the multiplicity of their purposes in using it. These authors have begun to articulate the range of user types, including teachers, learners, technical support staff, technical developers, educational developers, librarians, managers and evaluators. Thus there are many more communities between whom communication is necessary than have been discussed hitherto in the context of mediating representations, although Goodyear et al. (2004) in their work on patterns begin to address the gap between the more widely divergent communities of practitioners and technical developers. One of the conditions for the success of the Learning Activity Design in Education (LADiE) project was to bridge this gap.

\section{Methodology}

This paper takes a case study approach, which uses the experience of the LADiE project (http://www.elframework.org/refmodels/ladie; funded by the JISC) as a test bed for exploring a number of issues of the role of representations in transferring knowledge and understanding between different communities. 
The project faced the challenge of translating teaching practice in post-compulsory education across a community boundary into terms that were useful to technical developers. These experiences are situated in recent literature on the role of mediating representations and artefacts, which provides the concepts used to analyse reflections.

\section{The LADiE project: initial approach}

The JISC-funded LADiE project was a contribution to the development of the JISCDEST e-Framework for Education and Research being developed jointly by the JISC and the Australian Department for Education, Science and Training (DEST) (http:/ /www.e-framework.org/). The e-Framework supports a service-oriented approach to the development and delivery of education. This approach reflects a move from monolithic, powerful but inflexible virtual learning environments, towards a more flexible linking of individual 'service' components (such as chat and assessment tools, etc.) via loosely coupled, standards-based, interfaces. Essential to its development is the documenting of user requirements and processes in a coherent way, and to use these to derive a set of interoperable network services that conform to appropriate standards. The requirements are being documented in the form of 'reference models' or 'domain maps' that will enable members of the community to collaborate in the development of service components that meet their needs (Olivier et al., 2005). Thus, it is suggested, a 'reference model' will provide a mediating representation that enables practitioners and technical developers to communicate about their requirements (Figure 2).

A reference model provides:

- An abstract model of what has to be accomplished to meet the needs addressed.

- The description of the chosen means of implementing this model — defined by existing and developing technologies, specifications and standards (Olivier et al., 2005).

The aim of the LADiE project was to develop a learning activity reference model that was firmly based in practical experience of teaching and learning (http:// www.elframework.org/refmodels/ladie). In this case, the needs were defined as those

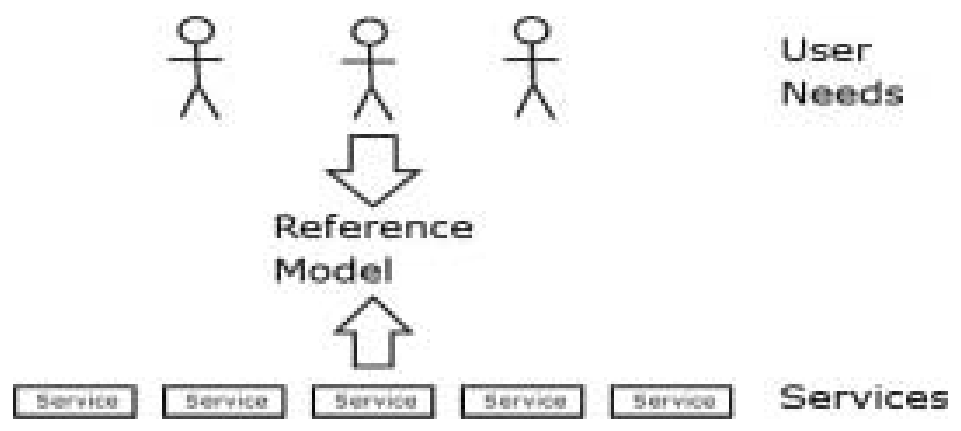

Figure 2. A reference model is a mediating representation that enables users to communicate their requirements for the services system 
of effective reusable learning activities. Therefore LADiE planned to use a 'top-down' and 'bottom-up' approach, documenting the requirements of effective learning activities in the form of 'use cases' through a series of practitioner workshops, and mapping these onto existing interoperability standards and specifications. Use cases are a way of specifying the behaviour requirements of a system, generally in a simple text form (Cockburn, 2001). They are mediating representations that serve to enhance communication about the ways in which the user needs a system to behave (Figure 3).

So we can see, already, in the initial project methodology, recognition that two mediating representations, the use case and the reference model, and an intermediate community of learning technologists, seem necessary to bridge the communication gap between practitioners and technical developers, in developing the web services system. The communication looks more like Figure 4 than Figure 2.

\section{The LADiE project: experience}

The project eventually documented 16 learning activities, gathered mainly from three one-day practitioner workshops. The 30 participants were a roughly equal mix of practitioners from higher education and further education, educational developers plus a couple of secondary school teachers. They were known to be e-learning enthusiasts and were invited for this reason. The aim was to document activities covering a wide range of possible teaching approaches and subject disciplines. Interviews with individual practitioners were used to fill in disciplinary gaps in workshop participation.

The initial intention was to get the practitioners themselves to document their activities in the form of use cases, by providing them with templates similar to that of Figure 3, and guiding them through the writing process. We tried this in our first workshop, but it proved extremely difficult to implement in the time available. Even with the scaffolding provided by the templates, and experts on hand to mediate the process, considerably more experience of writing use cases would be necessary before this community could utilise this type of representation of their practice effectively. The main two difficulties, even for this relatively expert group of participants, were in:

- decontextualising the learning activity and concentrating on the structure of the process; and

- separating the roles and actions of the practitioner in the process from the aims of the learner.

As noted in other studies, the practitioner community is accustomed to representing its practice in heavily contextualised forms, generally case studies (Sharpe et al., 2004; Falconer \& Littlejohn, 2006). In the LADiE project it seemed that this customary practice was too far removed from that of the learning technologists developing a reference model for the gap to be bridged by a single representation type, a use case, without a great deal of further and peripheral communication that would bring the communities closer together. Given the time constraints highlighted by Beetham (2001), this means that the use case representation is unlikely to be effective in this user context. 
Use Case Summary

Teacher runs an online a discussion conference with students

Primary Actor (and goal)

\begin{tabular}{|l|l|}
\hline Teacher & To administer the discussion conference successfully \\
\hline
\end{tabular}

Other Actors (and goals)

\begin{tabular}{|l|l|}
\begin{tabular}{|l|l|}
\hline Students & $\begin{array}{l}\text { To engage in dialogue and develop concepts to pass the } \\
\text { course }\end{array}$ \\
\hline Moderator & $\begin{array}{l}\text { To keep conference running smoothly, both socially and } \\
\text { organisationally }\end{array}$ \\
\hline
\end{tabular} \\
\begin{tabular}{|l|l|}
\hline 1 & System with conferencing facilities
\end{tabular} \\
\hline
\end{tabular}

Main Success Scenario

\begin{tabular}{|l|l|}
\hline 1 & $\begin{array}{l}\text { Teacher sets up small group conferences in system and defines student } \\
\text { groups }\end{array}$ \\
\hline 2 & System attaches students to teacher-defined discussion groups \\
\hline 3 & Students discuss asynchronously in small group conferences \\
\hline 4 & Teacher monitors small group conferences \\
\hline 5 & System saves records of conferences \\
\hline 6 & Students access saved conferences for future work \\
\hline
\end{tabular}

\section{Extensions}

1a Teacher is overworked and will not have time to monitor conferences

1a1 Teacher appoints student moderators for conferences

3a Some messages are inappropriate

3a1 Moderators edit or remove messages

4a Student participation is low

4a1 Teacher changes conference structure so new messages are more easily visible (e.g. by doing away with subconferences)

Figure 3. Abbreviated example of a use case specifying the requirements for running an online discussion conference derived from the LADiE project 


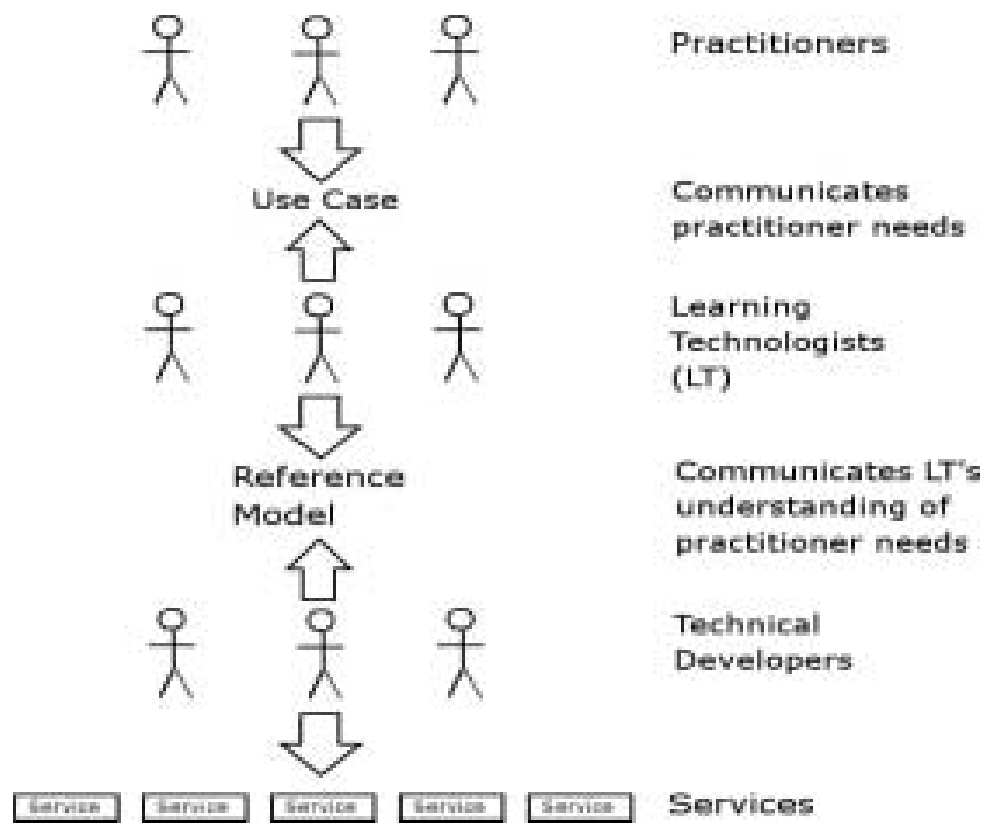

Figure 4. Communication structure and mediating representations implied by the proposed LADiE methodology

In subsequent LADiE workshops we abandoned this approach, and, instead, asked participants to document their activities as case studies. We provided templates that prompted them to detail the teaching context and learner needs explicitly, alongside a stepwise description of what they, and their students, did during the activity (http:/ /www.elframework.org/refmodels/ladie/guides/LARM_Pedagogy30-03-06.doc). This approach seemed to work far better from the practitioner's perspective. We then took these case studies and derived use cases from them, consulting back to the casestudy authors to check our interpretations.

The main communication around the developing use cases, however, was among the learning technologists in the LADiE team. This demonstrated clearly that we were two different, although overlapping, communities of learning technologistspractitioner focused and technically focused (the project team was deliberately put together in this way to implement the top-down, bottom-up approach) - and that a substantial amount of communication between the two was necessary to develop a representation that was meaningful and fit for purpose for both. This supports Sharpe et al.'s suggestion that representations of practice should be 'enhanced by their participation in collaborative activities' (Sharpe et al., 2004). Problems and misunderstandings negotiated through this process included:

- Granularity and aggregation - the granularity of a learning activity was the subject of much debate at workshops but most participants settled on something that had a definable beginning, middle and end, generally in the form 'provide students with 
some information, set a task based on the information, report on the result of the task'. Such activities comprised a number of different subactivities (e.g. information gathering, discussion forum, report writing), but these tended to be similar from one activity to another. In writing the use cases it often proved more effective to disaggregate these subactivities and re-aggregate the functionality required of similar ones together into generic use cases such as the discussion shown in Figure 3.

- Breadth versus depth - the initial conception of the practitioner-focused team members was that the documented learning activities should cover as wide a range of service components as possible. However, negotiation over the form of the use cases demonstrated that this supposition was based on a false assumption of the sophistication of existing interoperability standards. What the technically focused team members needed was to develop a core reference model based on an in-depth analysis of the requirements of a limited number of core functions such as discussions and quizzes. The purpose of the case studies, from their viewpoint, was to identify which these core functions were.

Thus, collaborating over development of use cases proved a very effective means of bridging this partial gap between the two overlapping communities of learning technologists.

Thus, the eventual structure and mediating representations that proved necessary in the LADiE project to provide meaningful communication between all communities of users looked something like Figure 5.

However, once the project was completed and the reference model written, these active communications disappeared. The reference model was written in three

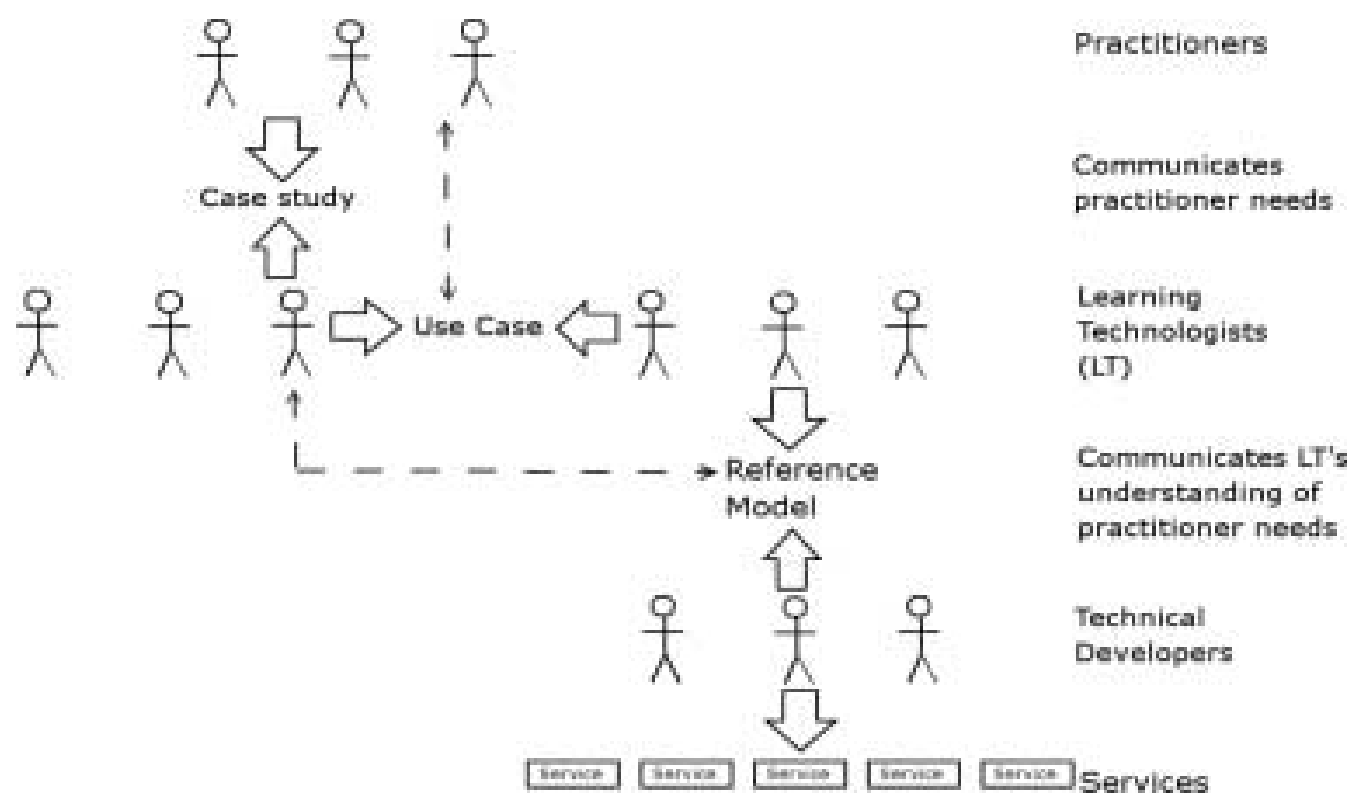

Figure 5. Communication structure and mediating representations used in the LADiE project 
parallel parts, aimed at technical developers, learning technologists and practitioners, reflecting recognition that the practices and purposes of these communities are sufficiently different that a single representation would not be meaningful to all of them. Once written and stabilised, it was envisaged that the reference model would mediate between users and services as in Figure 1. As in the case of Conole and Fill's DialogPlus toolkit, the role of the originating participants (practitioners and learning technologists) is hidden, embedded within the model, and the model could be viewed as a tool for the user. In this case it might be more appropriate to consider the model as a mediating artefact, in line with Conole's perspective, than as a mediating representation that enhances communication. It is early days yet to tell whether it will be possible to use the reference model unambiguously in this way, or whether as noted by Conole (2006) such a formalised representation leaves sufficient gaps of interpretation that communication between the end user and the originator or another 'expert' is necessary for effective use.

\section{Discussion}

Our experience as users of representations to mediate communication between a variety of communities has shown that the process is considerably more complex than is apparent from previous studies in the learning technology literature based on single or closely related communities.

In particular, it seems that gaps between some communities, even those united around a common endeavour such as teachers communicating their needs to technical developers, are too wide to be bridged by a single type of representation. In the LADiE project it took at least three communication steps-each centred around a different type of mediating representation, and involving two intermediate communities of participants - to migrate a concept of system requirements from practitioner to technical developer. In each of these steps the communities overlapped: practitioners-practitioner-focused learning technologists; practitioner-focused-technicallyfocused learning technologists; technically-focused learning technologists-technical developers. The overlap allowed active reciprocal communication between originators and end users around the representation - that this is necessary is for migrating concepts is suggested by Sharpe et al. (2004) and by Conole's (2006) work on effective mediation, and is assumed in our definition of a mediating representation.

The necessity we found for overlap between communities supports an interpretation of our representations as boundary objects that enabled a transfer of concepts from one community to another. At each step the practices of both communities encompassed the representation used, although they viewed it from different perspectives. Eventually, a chain of such steps allowed us to transfer concepts from the practitioner to technical developer communities.

In the LADiE project the overlapping communities were sufficiently close in their practices, language and modes of thinking to be able to communicate around the representation within a reasonable time frame. The time-driven constraints on effective representations noted by Beetham $(2001,2002)$ and Conole (2006) were most 
apparent at the first stage, documenting practitioners' learning activities. They became less significant at the second and third stages where participants (project team members) were being rewarded explicitly for communicating concepts. In developing the use cases, when relatively free from time constraints, we had representations that seemed both information rich and highly adoptable by learning technologists. However, the same representations proved neither adoptable nor informative to the practitioner community, and this underlines the obvious point that representations need to be tailored to the practice of their participants. When we consider the number of different combinations of communities that may need to communicate or collaborate during e-learning projects, the complexity of finding appropriate representations becomes apparent.

Finally, I suggest that, as the mediating representations reach a stable form and cease to be the locus of reciprocal communication, it may be possible to view them instead as 'mediating artefacts' or tools, in line with Conole's work. Thus, as implied by our initial overview, the distinction between 'mediating representation' and 'mediating artefact' is one of the processes employed and the context of use, rather than of the nature of the resources.

\section{Conclusions}

I have used the experience of the LADiE project as a case study of the processes involved in communicating ideas between different communities. These processes have been articulated in terms of the concepts of mediating representations, mediating artefacts and boundary objects. Our experience supports the following conclusions:

- The process of using representations to communicate between different communities is considerably more complex than hitherto recognised in the learning technology literature.

- For effective communication, communities must overlap, and the representations used should be common to both, forming 'boundary objects'.

- If communities do not overlap, then a series of communications between intermediate, and overlapping, communities is necessary using representations appropriate to each step.

- A significant number of different representation forms are needed to support communication between the large number of combinations of communities that may need to communicate or collaborate during e-learning projects.

- The counterposition between informative and adoptable, or acquirability and expressiveness, noted in the literature is a consequence of time constraints, as suggested by Beetham. For effective communication, time has to be made available.

- In a 'mediating artefact' the input of the originating community is embedded and hidden, but is still present: the distinction between 'mediating representation' and 'mediating artefact' depends on the context of use, rather than on the nature of the resource. 


\section{Acknowledgements}

The author thanks the other members of the LADiE project team, especially Allison Littlejohn, Gráinne Conole, Ann Jeffrey and Peter Douglas, for their support on the project, and thanks the JISC and the University of Dundee for financial and institutional support. An earlier version of this paper was given at the Networked Learning Conference, Lancaster, UK, April 2006.

\section{References}

Beetham, H. (2001) How do representations of practice enable practice to change?, Educational Developments, 2(4), 19-22.

Beetham, H. (2002) Developing learning technology networks through shared representations of practice, in: C. Rust (Ed.) Improving student learning through learning technologies (Oxford, Oxford Centre for Staff and Learning Development).

Beetham, H. (2004) Review: developing e-learning models for the fISC practitioner communities: a report for the FISC e-pedagogy programme (Bristol, JISC). Available online at: http:// www.jisc.ac.uk/uploaded_documents/Review\%20models.doc (accessed 22 June 2007).

Boose, J. H. (1990). Knowledge acquisition tools, methods, and mediating representations, in: H. Motoda, R. Mizoguchi, J. H. Boose \& B. R. Gaines (Eds) Proceedings of the First fapanese Knowledge Acquisition for Knowledge-Based Systems Workshop: FKAW-90 (Tokyo, Ohmsha Ltd).

Britain, S. \& Liber, O. (2004) A framework for pedagogical evaluation of virtual learning environments, FISC e-learning pedagogies programme report (Bristol, JISC). Available online at: http:// www.jisc.ac.uk/uploaded_documents/jtap-041.doc (accessed 22 June 2007).

Cockburn, A. (2001) Writing effective use cases (Boston, MA, Addison-Wesley).

Collis, B. \& van der Wende, M. (2002) Models of technology and change in higher education (Twente, Center for Higher Education Policy Studies), 85.

Collis, B. \& Moonen, J. (2005) An on-going journey: technology as a learning workbench, Faculty of Behavioural sciences, University of Twente. Available online at: http://bettycollisjefmoonen. $\mathrm{nl} / \mathrm{rb}$.htm (accessed 22 June 2007).

Conole, G. (2004). Report on the effectiveness of tools for e-learning: report for the FISC commissioned 'Research Study on the Effectiveness of Resources, Tools and Support Services used by Practitioners in Designing and Delivering E-Learning Activities' (Bristol, JISC). Available online at: http:// www.jisc.ac.uk/uploaded_documents/Report $\% 20$ on $\% 20$ the $\% 20$ effectiveness $\% 20$ of $\% 20$ tools \%20v5_Martin_Oliver.doc (accessed 22 June 2007).

Conole, G. (2006) Mediating artefacts to guide choice in creating and undertaking learning activities, in: S. Banks, V. Hodgson, C. Jones, B. Kemp, D. McConnell \& Ch. Smith (Eds) Proceedings of the Fifth International Conference on Networked Learning 2006 (Lancaster, Lancaster University).

Conole, G. \& Dyke, M. (2004) What are the affordances of information and communication technologies?, $A L T-\mathcal{F}, 12(2), 111-122$.

Conole, G. \& Fill, K. (2005) A learning design toolkit to create pedagogically effective learning activities, fournal of Interactive Media in Education, 8. Available online at: www-jime.open. ac.uk/2005/08/conole-2005-08.pdf (accessed 22 June 2007)

Conole, G. \& Oliver, M. (2001) Decision-making resources for embedding theory into practice, in: T. Okamoto et al. (Eds) Proceedings IEEE International Conference on Advanced Learning Technology: Issues, Achievements and Challenges, 6-8 August (Washington, DC, IEEE Computer Society), 327-330.

Conole, G. \& Oliver, M. (Eds) (2007) Contemporary perspectives in e-learning research: themes, methods and impact on practice (London, RoutledgeFalmer). 
Edwards, R. (2005) Contexts, boundary objects and hybrid spaces: theorising learning in lifelong learning, paper presented at the 35th Annual SCUTREA Conference, University of Sussex, UK, 5-7 July. Available online at: http://www.leeds.ac.uk/educol/documents/142037.htm (accessed 28 January 2007).

Engeström, Y., Miettinen, R. \& Punamäki, R. (1999) Perspectives on activity theory (Cambridge, Cambridge University Press).

Falconer, I. \& Littlejohn, A. (2006) Mod4L report: case studies, exemplars and learning designs. Mod4L project report for JIS C. Available online at: http://mod41.com/tiki-download file.php?fileId=2 (accessed 29 January 2007).

Falconer, I., Beetham, H., Oliver, R., Lockyer, L. \& Littlejohn, A. (2007) Mod4L final report: representing learning designs. Report from the JISC Mod4L project. Available online at: http:// mod41.com/tiki-download_file.php?fileId=7 (accessed 22 June 2007).

Fowler, C. J. H. \& Mayes, T. (1999) Learning relationships from theory to design, ALT-f, 7(3), 6-16.

Goodyear, P. \& Steeples, C. (1998) Creating shareable representations of practice, $A L T-f, 6(3)$, $16-23$.

Goodyear, P., Avgeriou P., et al. (2004) Towards a pattern language for networked learning, paper presented at the Networked Learning Conference 2004. Available online at: http://www.networkedlearningconference.org.uk/past/nlc2004/proceedings/individual_papers/goodyear_et_al.htm (accessed 22 June 2007).

JISC (2006) Circular for design for learning funding call. Available online at: http://www.jisc.ac.uk/ index.cfm?name=funding_01_06 (accessed 22 June 2007).

Jones, C. \& Conole, G. (2006) Who will own the new VLE? Sharing practice, problems and alternative solutions, paper presented at the Proceedings of the 23rd Annual Ascilite Conference: Who's learning? Whose technology? Available online at: http://www.ascilite.org.au/conferences/ sydney06/proceeding/pdf_papers/p95.pdf (accessed 22 June 2007).

Leadbetter, J. (2004) The role of mediating artefacts in the work of educational psychologists during consultative conversations in schools, Educational Review, 56(2), 133-145.

Littlejohn, A. (2004) The effectiveness of resources, tools and support services used by practitioners in designing and delivering e-learning activities: final report (Bristol, JISC). Available online at: http://www.elearning.ac.uk/ resources/effectivefinal/view (accessed 22 June 2007).

Littlejohn, A. \& Peacock, S. (2003) From pioneers to partners: the changing voices of staff developers, in: J. K. Seale (Ed.) Learning technology in transition: from individual enthusiasm to institutional implementation (Lisse, Swets and Zeitlinger).

Littlejohn, A., Falconer, I. \& McGill, L. (2006) Characterising effective e-learning resources, Computers and Education. Available online at: http://www.sciencedirect.com/science?_ob= ArticleURL\&_udi=B6VCJ-4M21SW7-1\&_user $=128597 \&$ _coverDate $=10 \% 2 \mathrm{~F} 05 \% 2 \mathrm{~F} 2006 \&$ _alid $=521904214 \& \_r d o c=1 \& \_f m t=$ full\&_orig $=$ search\&_cdi $=5956 \& \_s o r t=d \& \_d o c a n c h o r=\& v$ iew $=$ c\&_acct $=\mathrm{C} 000010621 \&$ \& version $=1 \&$ \&urlVersion $=0 \&$ \& userid $=128597 \& \mathrm{md} 5=\mathrm{f} 6 \mathrm{fdcb} 190$ e3576b4a7f79a80ade2e108(accessed 5 October 2006).

Mayes, T. (2001) Learning technology and learning relationships, in: J. Stephenson (Ed.) Teaching and learning online (London, Kogan Paul), 16-26.

Oliver, M. (2004) Assessing the relevance of the review of e-learning theories, frameworks and models and the mapping table to evaluators. JISC e-learning models desk study, (Bristol, JISC), 7. Available online at: http://www.jisc.ac.uk/uploaded_documents/Evaluators.doc (accessed 22 June 2007).

Oliver, R. (2006) Ronline: mediating artefacts to support technology-facilitated learning, in: A. Bunker \& I. Vardi (Eds), Critical visions: thinking, learning and researching in higher education (Milperra, NSW, HERDSA), 259-267.

Olivier, B., Roberts, T. \& Blinco, K. (2005) The e-framework for education and research: an overview. Paper prepared on behalf of DEST (Australia), JISC-CETIS (UK). Available online at: http://www.e-framework.org/resources/eframeworkrV1.pdf (accessed 22 June 2007). 
Scott, J. (2004) Assessing the relevance of the review of e-learning theories, frameworks and models and the mapping table to designers. JISC e-learning models desk study (Bristol, JISC), 9. Available online at: http://www.jisc.ac.uk/uploaded_documents/Designers.doc (accessed 22 June 2007).

Seufert, S. \& Euler, D. (2004) Sustainability of e-learning innovations-findings of expert interviews. SCIL Report 2 (St Gallen, SCIL University of St Gallen).

Sharpe, R., Beetham. H. \& Ravenscroft, A. (2004) Active artefacts: representing our knowledge of learning and teaching, Educational Developments, 5(2), 16-21.

Star, S. L. (1989) The structure of ill-structured solutions: boundary objects and heterogeneous distributed problem solving, in: L. Gasser \& M. Huhns (Eds) Distributed artificial intelligence (vol. II) (London, Pitman).

Tuomi-Grohn, T. \& Engestrom, Y. (Eds) (2003) Between work and school: new perspectives on transfer and boundary-crossing (London, Pergamon).

Wenger, E. (1998) Communities of practice: learning, meaning, and identity (Cambridge, Cambridge University Press). 